\title{
Drug-Induced Hypothyroidism during Anti-Tuberculosis Treatment of Multidrug-Resistant Tuberculosis: Notes from the Field
}

\author{
Somashekar Munivenkatappa ${ }^{1,2 *}$, Singarajipura Anil33, Balaji Naik4, Tyson Volkmann5, \\ Karuna D. Sagili6, Jayachamarajapura S. Akshatha², Shashidhar Buggi', Manchenahalli A. Sharada7, \\ Sudhendra Kulkarni ${ }^{1}$, Vineet K. Chadha ${ }^{7}$, Patrick K. Moonan ${ }^{{ }^{*}}$ \\ ${ }^{1}$ Drug Resistant Treatment Centre, Bengaluru, India \\ ${ }^{2}$ Sri Devarao Shivaram, Tuberculosis and Rajiv Gandhi Institute of Chest Diseases, Bengaluru, India \\ ${ }^{3}$ Revised National Tuberculosis Programme-State of Karnataka, Bengaluru, India \\ ${ }^{4}$ World Health Organization, India Country Office, New Delhi, India \\ ${ }^{5}$ U.S. Centers for Disease Control and Prevention, Atlanta, GA, USA \\ ${ }^{6}$ International Union against Tuberculosis and Lung Disease (The Union), South-East Asia Regional Office, New Delhi, India \\ ${ }^{7}$ National Tuberculosis Institute, Bengaluru, India \\ Email: somu0108@gmail.com, ’pmoonan@cdc.gov
}

How to cite this paper: Munivenkatappa, S., Anil, S., Naik, B., Volkmann, T., Sagili, K.D., Akshatha, J.S., Buggi, S., Sharada, M.A., Kulkarni, S., Chadha, V.K. and Moonan, P.K. (2016) Drug-Induced Hypothyroidism during Anti-Tuberculosis Treatment of Multidrug-Resistant Tuberculosis: Notes from the Field. Journal of Tuberculosis Research, 4, 105-110. http://dx.doi.org/10.4236/jtr.2016.43013

Received: June 21, 2016

Accepted: August 20, 2016

Published: August 23, 2016

Copyright $\odot 2016$ by authors and Scientific Research Publishing Inc. This work is licensed under the Creative Commons Attribution International License (CC BY 4.0).

http://creativecommons.org/licenses/by/4.0/ (c) (i) Open Access

\section{Abstract}

We followed 188 euthyroidic persons undergoing treatment for multidrug resistant tuberculosis (MDR-TB) in the state of Karnataka, India to determine the incidence of hypothyroidism during anti-tuberculosis treatment. Overall, among MDR-TB patients with valid thyroid stimulating hormone (TSH) values, about $23 \%$ developed hypothyroidism ( $\mathrm{TSH}$ value $\geq 10 \mathrm{mIU} / \mathrm{ml}$ ) during anti-tuberculosis treatment; the majority (74\%) occurring after 3 months of treatment. Among 133 patients who received a regimen that contained ethionamide, 42 (32\%) developed hypothyroidism. Among 17 patients that received a regimen that contained para-aminosalicylate sodium, 6 (35\%) developed hypothyroidism. Among 9 HIV positive patients on antiretroviral treatment, 4 (44\%) developed hypothyroidism. These results differ from previously reported $4 \%$ incidence of hypothyroidism amongst patients who passively reported thyroidal symptoms during treatment, suggesting routine serologic monitoring of TSH throughout the course of treatment for MDR-TB is warranted.

\section{Keywords}

Hypothyroidism, Multidrug Resistance, Tuberculosis, Thyroid-Stimulating 
Hormone, India

\section{Introduction}

Multidrug-resistant tuberculosis (MDR-TB) is defined as tuberculosis (TB) that is resistant to isoniazid and rifampicin, the two most efficacious anti-TB drugs [1]. MDR-TB has emerged as a major threat to TB control in India with approximately 62,000 new cases occurring annually [1] [2]. In Karnataka state, India, Programmatic Management of Drug-resistant TB (PMDT) started in 2011. All patients with laboratoryconfirmed drug-resistant TB are treated with a standard regimen; this includes an intensive phase consisting of kanamycin, cycloserine, levofloxacin, ethionamide, ethambutol, and pyrazinamide for 6 - 9 months followed by a continuation phase of 18 months with cycloserine, levofloxacin, ethionamide, and ethambutol [2]. In the event of drug intolerance or severe adverse reactions to kanamycin and cycloserine, paraaminosalicylate sodium (PAS) may be used as a substitute drug [3]. PAS and ethionamide are known to cause hypothyroidism [4]. Anti-retroviral drugs (stavudine, didanosine, and protease inhibitors) used for treatment of HIV can also cause hypothyroidism [5]. According to studies carried out elsewhere, 54\% - 69\% of patients might develop hypothyroidism during treatment for MDR-TB [6]-[8].

Under PMDT, serologic testing for thyroid-stimulating hormone (TSH), a biomarker for thyroid functioning, is conducted only amongst MDR-TB patients who passively report experiencing signs and symptoms of hypothyroidism. However, because hypothyroidism often presents with sub-clinical manifestations that are often masked by other conditions (e.g., arthralgia, depression, ectodermal dysplasia, psychosis, and xeroderma), it may be underdiagnosed [9]. Thus, we conducted a prospective study to find the proportion of cases that develop hypothyroidism during intensive phase of MDR-TB treatment, using routine serological TSH testing.

\section{Materials and Methods}

\subsection{Patient Selection}

All adult ( $\geq 15$ years of age) patients registered under PMDT in Karnataka during October, 2014-March, 2015 were eligible for enrolment. Those not willing to provide written informed consent or found suffering from hypothyroidism during pre-treatment evaluation were excluded.

\subsection{Serological Testing}

Serologic TSH levels were obtained at baseline, at end of 3 and 6 months of antituberculosis treatment using an ultrasensitive sandwich chemi-luminesent-immunologic assay at a private laboratory in Bangalore accredited by the College of American Pathologist and National Accreditation Board for Testing Calibration. Hypothyroidism was defined as TSH value $\geq 10 \mathrm{mIU} / \mathrm{ml}$ irrespective of clinical symptoms. Patients found 
suffering from hypothyroidism were provided free treatment with levothyroxine according to international guidelines [9].

\subsection{Data Collection Data Management and Statistical Analysis}

Patient characteristics, anti-tuberculosis drugs prescribed, and TSH values were obtained from the PMDT register, treatment cards and laboratory reports. Data was recorded in a structured data collection sheet, double entered, validated and analysed using EpiData software (EpiData Association, Odense, Denmark).

Proportions developing hypothyroidism and 95\% confidence intervals (CI) were calculated. Chi-square was used to detect differences in proportions that developed hypothyroidism (alpha $<0.05)$.

\subsection{Ethical Considerations}

The study was approved by the Institutional Ethics committees of Rajiv Gandhi Institute of TB and Chest Diseases, Bangalore, National Tuberculosis Institute, Bangalore, the Ethics Advisory Group, International Union Against Tuberculosis and Lung Disease (The Union), and the Division of Global HIV and Tuberculosis, Centers for Disease Control and Prevention, Atlanta, GA USA

\section{Results}

Of 194 persons being treated for MDR-TB, 5 (2.5\%) patients did not receive a TSH test at baseline, and one was found to be suffering from hypothyroidism during pre-treatment evaluation; these patients were excluded from analysis. Of the remaining 188 patients, 165 (88\%) received ethionamide, 5 (3\%) received PAS and 18 (10\%) both PAS and ethionamide. There were 19 patients who were HIV positive, 9 received ART. Excluding those who died $(n=7)$, lost to follow-up $(n=12)$ and transferred out $(n=1)$ by the third month, 168 were eligible for TSH testing. Of them, 33 were not tested due to for various programmatic reasons. At 3 months, 135 (80\%) were tested of which 12 developed hypothyroidism. Excluding those that had developed hypothyroidism by 3 months, 123 were eligible for TSH testing at 6 months. Of them, 8 were not tested. Of 115 tested, 31 additional patients developed hypothyroidism between 3 and 6 months. Thus overall, 43 (23\%) developed hypothyroidism during anti-tuberculosis treatment (95\% CI: 17\% - 29\%).

With the exception of females in the first three months of anti-tuberculosis treatment ( $17 \%$ females vs $5 \%$ males; $p=0.018$ ), overall risk of developing hypothyroidism was not found related to age, sex or medication received (Table 1). It is worth noting, however, that among 133 patients who received a regimen that contained ethionamide, 42 (32\%) developed hypothyroidism. Among 17 patients that received a regimen that contained PAS, 6 (35\%) developed hypothyroidism. Also among 9 HIV positive patients on ART, 4 (44\%) developed hypothyroidism.

\section{Discussion}

Among MDR-TB patients with valid TSH values, about 23\% developed hypothyroidism 
Table 1. Demographic and treatment characteristics of patients receiving antituberculosis drug treatment for multidrug-resistant tuberculosis by thyroid stimulating hormone testing-Karnataka, India, October 2014 through January 2015.

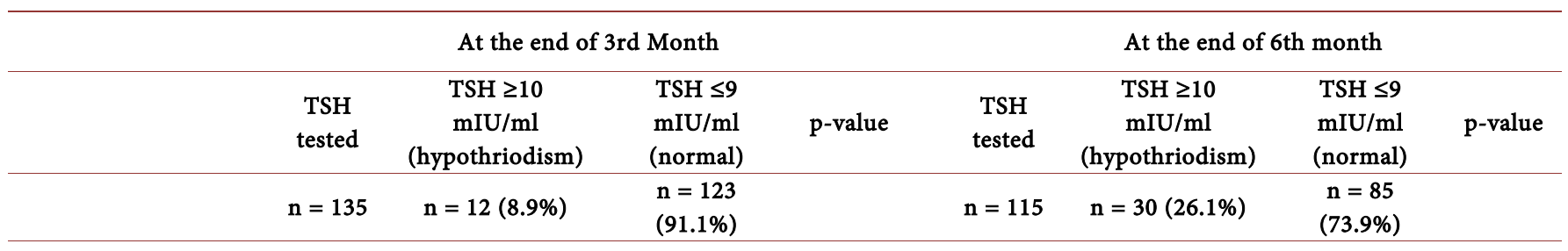

\section{Characteristic}

\begin{tabular}{|c|c|c|c|c|c|c|c|c|c|c|c|c|}
\hline $\begin{array}{c}\text { Age } \\
\text { (in years) }\end{array}$ & & & & & & 0.65 & & & & & & 0.74 \\
\hline$<15$ & 1 & 0 & $0.0 \%$ & 1 & $100.0 \%$ & & 1 & 0 & $0.0 \%$ & 1 & $100.0 \%$ & \\
\hline $15-24$ & 21 & 4 & $19.0 \%$ & 17 & $81.0 \%$ & & 17 & 4 & $23.5 \%$ & 13 & $76.5 \%$ & \\
\hline $25-34$ & 36 & 2 & $5.6 \%$ & 34 & $94.4 \%$ & & 31 & 7 & $22.6 \%$ & 24 & $77.4 \%$ & \\
\hline $35-44$ & 33 & 3 & $9.1 \%$ & 30 & $90.9 \%$ & & 31 & 10 & $32.3 \%$ & 21 & $67.7 \%$ & \\
\hline $45-54$ & 19 & 2 & $10.5 \%$ & 17 & $89.5 \%$ & & 18 & 6 & $33.3 \%$ & 12 & $66.7 \%$ & \\
\hline $55-64$ & 21 & 1 & $4.8 \%$ & 20 & $95.2 \%$ & & 13 & 2 & $15.4 \%$ & 11 & $84.6 \%$ & \\
\hline$>65$ & 4 & 0 & $0.0 \%$ & 4 & $100.0 \%$ & & 4 & 2 & $50.0 \%$ & 2 & $50.0 \%$ & \\
\hline \multicolumn{13}{|l|}{ Sex } \\
\hline Female & 48 & 8 & $16.7 \%$ & 40 & $83.3 \%$ & 0.02 & 38 & 7 & $18.4 \%$ & 31 & $81.6 \%$ & 0.15 \\
\hline Male & 87 & 4 & $4.6 \%$ & 83 & $95.4 \%$ & & 77 & 24 & $31.2 \%$ & 53 & $68.8 \%$ & \\
\hline \multicolumn{13}{|l|}{$\begin{array}{c}\text { Medication } \\
\text { Received }\end{array}$} \\
\hline thiomide $(\mathrm{ETH})$ & 118 & 11 & $9.3 \%$ & 107 & $90.7 \%$ & 0.64 & 99 & 26 & $26.3 \%$ & 73 & $73.7 \%$ & 0.68 \\
\hline $\begin{array}{l}\text { Para-amino } \\
\text { salicylate } \\
\text { sodium (PAS) }\end{array}$ & 2 & 0 & $0.0 \%$ & 2 & $100.0 \%$ & -- & 2 & 1 & $50.0 \%$ & 1 & $50.0 \%$ & 0.97 \\
\hline $\begin{array}{l}\text { Both PAS } \\
\text { and ETH }\end{array}$ & 15 & 1 & $6.7 \%$ & 14 & $93.3 \%$ & 0.75 & 14 & 4 & $28.6 \%$ & 10 & $71.4 \%$ & 0.75 \\
\hline $\begin{array}{c}\text { Antiretroviral } \\
\text { drugs }\end{array}$ & 19 & 2 & $10.5 \%$ & 17 & $89.5 \%$ & 0.79 & 19 & 9 & $47.4 \%$ & 10 & $52.6 \%$ & 0.72 \\
\hline \multicolumn{13}{|c|}{$\begin{array}{l}\text { TSH }=\text { thyroid stimulating hormone measured at } \\
\text { mirco-international units per millilitre. } \\
\text { p-value for } \\
\text { earson's chi-square }\end{array}$} \\
\hline
\end{tabular}

during antituberculosis treatment, with the majority (74\%) occurring after 3 months of treatment. These results differ from a report using routine programmatic monitoring data (TSH conducted only among symptomatic patients) where $4 \%$ developed hypothyroidism [10]. These results suggest that serological TSH monitoring may be important 
throughout the course of MDR-TB treatment. All patients should receive serological TSH monitoring during MDR-TB treatment to detect subclinical cases of hypothyroidism, which if not treated may lead to poor quality of life, and unfavourable outcomes including death and loss to follow-up. Findings of this study could have application to all patients treated under PMDT in India. A limitation of the present study was that TSH testing was performed only at the third and sixth months of treatment. It is likely that testing at more regular intervals and throughout the entire length of MDR-TB treatment would increase the time to detection of hypothyroidism. Future studies are needed to find out the proportion of MDR-TB patients developing hypothyroidism during continuous phase as well, as susceptibility for hypothyroidism may continue beyond IP. A substantial number of patients (11\%) either died or were lost to follow-up. It is possible that some these patients may have suffered from hypothyroidism, thus underestimating incidence.

\section{Conclusion}

Undiagnosed hypothyroidism has serious potential sequelae to MDR-TB patients and increases the risk for additional physical and mental health problems. The current PMDT policy of waiting for thyroidal symptoms to develop may underestimate the true burden and put patients at unnecessary risk and worsen clinical outcomes. Routine TSH testing should be considered for all patients receiving anti-tuberculosis treatment for MDR tuberculosis, especially those receiving regimens containing PAS and ethionamide or antiretrovirals.

\section{Acknowledgements}

The study was undertaken as a part of the "TB Operations Research Training Project" conducted by The International Union against TB and Lung Disease (The Union) with funding support from The Global Fund through Project Axshya. This training project was conceived and implemented by The Union (South-East Asia Regional Office, New Delhi, India) in collaboration with Central TB Division (Directorate General of Health Services, Ministry of Health and Family Welfare, Government of India), the National TB Institute (Directorate General of Health Services, Ministry of Health and Family Welfare, Government of India Bangalore, India), World Health Organization (India Country Office), and U.S. Centers for Disease Control and Prevention (Division of Global HIV and Tuberculosis).

\section{Conflict of Interest}

No conflicts declared.

\section{Disclaimer}

The findings and conclusions in this paper are those of the authors and do not necessarily reflect the official position of the U.S. Centers for Disease Control and Prevention or the World Health Organization. 


\section{References}

[1] World Health Organization (2015) Global Tuberculosis Report, 2014 (Drug-Resistant TB, Surveillance and Response) World Health Organization. Geneva, Switzerland. [WHO/ $\mathrm{HTM} / \mathrm{TB} / 2015.07]$.

[2] Central Tuberculosis Division, Directorate General of Health Services (2012) Revised National Tuberculosis Control Programme, Guidelines on programmatic management of drug-resistant tuberculosis (PMDT) in India. Available at:

https://www.medbox.org/guidelines-on-programmatic-management-of-drug-resistant-tb-p mdt-in-india-1/preview

[3] Macgregor A.E. and Somner, A.R. (1954) The Anti-Thyroid Action of Para-Aminosalicylic Acid. The Lancet, 264, 931-936. http://dx.doi.org/10.1016/S0140-6736(54)92552-0

[4] Drucker, D., Eggo, M.C., Salit, I.E. and Burrow, G.N. (1984) Ethionamide-Induced Goitrous Hypothyroidism. Annals of Internal Medicine, 100, 837-839. http://dx.doi.org/10.7326/0003-4819-100-6-837

[5] Silva, G.A., Andrade, M.C., Suguide, A., et al. (2015) Association between Antiretrovirals and Thyroid Diseases: Across-Sectional Study. Archives of Endocrinology and Metabolism, 59, 116-122. http://dx.doi.org/10.1590/2359-3997000000023

[6] Modongo, C. and Zetola, N.M. (2012) Prevalence of Hypothyroidism among MDR-TB Patients in Botswana. International Journal of Tuberculosis and Lung Diseases, 16, 1561-1562. http://dx.doi.org/10.5588/ijtld.12.0403

[7] Satti, H., Mafukidze, A., Jooste, P.L., et al. (2012) High Rate of Hypothyroidism among Patients Treated for MDR-TB in Lesotho. International Journal of Tuberculosis and Lung Diseases, 16, 468-472. http://dx.doi.org/10.5588/ijtld.11.0615

[8] Andries, A., Isaakidis, P., Das, M., et al. (2013) High Rate of Hypothyroidism in Multidrug-Resistant Tuberculosis Patients Co-Infected with HIV in Mumbai, India. PloS One, 10, e78313. http://dx.doi.org/10.1371/journal.pone.0078313

[9] Garber, J.R., Cobin, R.H., Gharib, H., et al. (2012) Clinical Practice Guidelines for Hypothyroidism in Adults: Cosponsored by the American Association of Clinical Endocrinologists and the American Thyroid Association. Thyroid, 22, 1200-1235. http://dx.doi.org/10.1089/thy.2012.0205

[10] Akshata, J.S., Swapna, R., Chakraboty, A. and Somashekar M. (2015) Hypothyroidism in MDR-TB Treatment-Rare Occurrence, but a Major Concern. Egyptian Journal of Chest Diseases and Tuberculosis, 64, 671-674. http://dx.doi.org/10.1016/j.ejcdt.2015.03.022 
Submit or recommend next manuscript to SCIRP and we will provide best service for you:

Accepting pre-submission inquiries through Email, Facebook, LinkedIn, Twitter, etc. A wide selection of journals (inclusive of 9 subjects, more than 200 journals)

Providing 24-hour high-quality service

User-friendly online submission system

Fair and swift peer-review system

Efficient typesetting and proofreading procedure

Display of the result of downloads and visits, as well as the number of cited articles

Maximum dissemination of your research work

Submit your manuscript at: http://papersubmission.scirp.org/ 